DOI: http://dx.doi.org/10.19177/reen.v9e12016265-292

http://portaldeperiodicos.unisul.br/index.php/EeN/index

\title{
DIAGNÓSTICO MERCADOLÓGICO NO SETOR DE VIDEO LOCADORAS: ESTUDO NA GRANDE FLORIANÓPOLIS/SC
}

\section{MARKETING DIAGNOSIS IN THE VIDEO RENTAL INDUSTRY: STUDY IN FLORIANÓPOLIS REGION/SC}

\section{DIAGNOSTICO DE MERCADO EN EL SECTOR DE ALQUILER DE VIDEO}

\author{
Aléssio Bessa Sarquis \\ Doutor em Administração pela Universidade de São Paulo (USP) \\ Professor do Programa de Pós-Graduação do Mestrado em Administração da Universidade Sul de \\ Santa Catarina (UNISUL) \\ Endereço: R. Trajano, n. 219, Centro, CEP: 88010 -010. Florianópolis, SC, Brasil \\ Telefone: (48) 3279-1932. E-mail: alessio.sarquis@unisul.br
}

\section{Mara Cristine Kich}

Mestre em Administração pela Universidade do Sul de Santa Catarina (UNISUL)

Professora da Faculdade Borges de Mendonça

Endereço: R. Santos Dumont, n. 104, Centro, CEP: 88015-020. Florianópolis, SC, Brasil

Telefone: (48) 3229-2500. E-mail: marakich@gmail.com

\section{Edson Roberto Scharf}

Professor do Programa de Pós-Graduação

Mestrado em Administração da Universidade Regional de Blumenau (FURB)

Formação acadêmica: Doutor em Engenharia e Gestão do Conhecimento na área de Marketing pela Universidade Federal de Santa Catarina (UFSC)

Endereço: Rua Antônio da Veiga, 140 - Itoupava Seca - CEP 89030-903 - Blumenau - SC

Telefone: 47 3321-0285. E-mail: talentto@terra.com.br

\section{Karina Ramos Wagner}

Graduanda em Administração da Universidade do Sul de Santa Catarina (UNISUL)

Endereço: Av. Pedra Branca, n. 25, Cidade Universitária Pedra Branca, CEP 88137-270. Palhoça, SC, Brasil

Telefone: (48) 3279-1932. E-mail: karinaramosw@gmail.com

\section{Lenoir Hoeckesfeld}

Mestrado em Administração da Universidade do Sul de Santa Catarina (UNISUL)

Endereço: R. Servidão Clodomiro Vicente da Silva, n. 60, apto 105, Bairro Saco dos Limões, CEP:

88045-543. Florianópolis, SC, Brasil

Telefone: (48) 3279-1932. E-mail: leno.adm@gmail.com

Artigo recebido em 14/03/2015. Revisado por pares em 19/04/2015. Reformulado em 19/04/2015. Recomendado para publicação em 23/04/2016, por Ademar Dutra (Editor Científico). Publicado em 30/04/2015. Avaliado pelo Sistema Double blind review. 


\section{RESUMO}

O setor de vídeo locadoras enfrenta graves ameaças de mercado. O presente estudo avalia a situação de marketing desse setor na Grande Florianópolis, em Santa Catarina. Pesquisa descritiva, quantitativa e na forma de levantamento de campo foi realizada com 26 vídeo locadoras. Os resultados confirmam que o setor está em declínio e que as principais ameaças são: a intensidade da pirataria, o download gratuito de filmes pela Internet, as vídeo locadoras virtuais, a televisão por assinatura, o uso da Internet/redes sociais pelos consumidores e a redução da demanda. $O$ estudo contribui para ampliar os conhecimentos sobre a situação do setor no Brasil.

Palavras-chave: Marketing de varejo; Diagnóstico mercadológico; Análise da situação de marketing; Análise setorial; Setor de vídeo locadoras.

\section{ABSTRACT}

The video rental industry faces serious market threat. This study evaluates the marketing situation of this sector in Florianópolis Region, Santa Catarina. Descriptive and quantitative research, in the form of field survey was carried out with 26 video rentals. The results confirm that the sector is in decline and that the main threats are the intensity of piracy, free download movies from the Internet, virtual video rentals, pay-TV, the use of Internet/social networking for consumers and reducing demand. The study contributes to broaden the knowledge of the sector's situation in Brazil.

Keywords: Retail marketing; Marketing diagnosis; Analysis of the marketing situation; Sectoral analysis; Video rental industry.

\section{RESUMEN}

El sector de alquiler de vídeo enfrenta graves amenazas de mercado. Este estudio evalúa la situación de marketing de ese sector en la Región de Florianópolis, en Santa Catarina. Investigación descriptiva, cuantitativa y en la forma de levantamiento de campo fue realizada con 26 tiendas de alquiler de video. Los resultados confirman que el sector está en disminución y que las principales amenazas son: la intensidad de la piratería, el download gratis de películas por la Internet, el alquiler virtual de videos, la televisión por firma, el uso de la Internet/redes sociales por los consumidores y la reducción de demanda. El estudio contribuye para ampliar los conocimientos sobre la situación del sector en Brasil.

Palabras-clave: Marketing de venta por al menor; Diagnóstico de mercado; Análisis de la situación de marketing; Análisis sectorial; Sector de alquiler de video. 
DIAGNÓSTICO MERCADOLÓGICO NO SETOR DE VIDEO LOCADORAS: ESTUDO NA GRANDE FLORIANÓPOLIS/SC

Aléssio Bessa Sarquis - Mara C. Kich - Edson Roberto Scharf - Karina R. Wagner - Lenoir Hoeckesfeld

\section{INTRODUÇÃO}

O marketing constitui uma função organizacional dirigida para o atendimento das necessidades e expectativas dos clientes e contribui para o desempenho mercadológico da organização(WESTWOOD, 2006; SARQUIS, 2009).Sabe-se que, quando está altamente satisfeito, o cliente tende a ser mais leal, a comprar com mais frequência, a falar mais positivamente sobre a organização, a dar menos atenção às marcas/produtos concorrentes, a ser menos sensível às ofertas de preços e a ser mais rentável(SASSER; SCHLESINGER; HESKETT, 1997; MCDONALD, 2006; FERRELL; HARTLINE, 2011).

A indústria de entretenimento (que inclui asvídeo locadoras) é um dos setores impactados pelo advento da Internet e pela evolução da tecnologia da informação (ALVES; DIAS; NOGUEIRA, 2010). Nele, a concorrência não se restringe às empresas do ramo de atividade, mas inclui televisão por assinatura, vídeo games, aparelhos de som e redes sociais na Internet, por exemplo. No Brasil, outros fatores de mercado ameaçam também a sobrevivência das vídeo locadoras, incluindo a pirataria física e on-line de filmes (SACRINI, 2005; FECOMÉRCIO-RJ, 2012). Há,ainda, indícios de deficiência na prática de marketing das organizações desse setor, como pouco conhecimento pouco investimento em marketing (ANACLETO; MICHEL, 2008; RITTER et al., 2009).

De Mello e Kliemann (2010) apontaram, também, que a Internet alterou a forma de relacionamento entre os agentes da indústria de entretenimento, acirrou as disputas comerciais, reduziu a distância entre os mercados e trouxe novos aspectos/fatores de estudo para o campo da estratégia empresarial. Assim, há necessidade de ampliar o conhecimento sobre a situação de marketing das vídeo locadoras no Brasil, um setor que fomenta a cultura e o entretenimento, principalmente nos municípios brasileiros com poucas salas de cinemas (ANACLETO; MICHEL, 2008) e onde a televisão por assinatura atinge apenas pequena parcela da população. A região da Grande Florianópolis/SC é um dos principais polos da indústria tecnológica do Brasil e inclui os municípios de São José, Palhoça e Biguaçu, onde a atividade econômica e a área de comércio e serviços é diversificada. Nessa região, o Núcleo das Vídeo locadoras da Câmara de Dirigentes Lojistas foi criado com propósito de apoiar a preservação do setor, diante da ausência de políticas públicas reguladoras e da intensidade da pirataria (CDL, 2013).

Revista Eletrônica de Estratégia \& Negócios, Florianópolis, v.9, n.1, jan./abr. 2016. 
Silveira e Erdmann (2010) apontaram que a administração baseada na visão segmentada dos problemas tende a gerar apenas melhorias pontuais, e que desconsideram a situação integral da organização. Diagnósticos são necessários para identificar adequadamente as deficiências e pontos fortes do setor/organização, e para a definição dos investimentos e aperfeiçoamentos necessários. Há carência de pesquisa acadêmica sobre a situação de marketing do setor de vídeo locadoras no Brasil (ANACLETO; MICHEL, 2008). Um levantamento feito por Sarquis e Pizzinatto (2012)apontou, também, que há, no contexto nacional, ainda poucos estudos sobre diagnóstico mercadológico no setor de serviços, e há carência de explicação sobre diagnósticos mercadológicos em organizações de pequeno porte.Um diagnóstico mercadológico pode auxiliar na identificação de dimensões de análises e categorias de dados no processo de diagnóstico mercadológico no setor de vídeo locadoras.

Com base nas constatações apresentadas, decidiu-se pela realização do presente estudo com a seguinte pergunta de pesquisa: Qual a situação de marketing do setor de vídeo locadoras na região Grande Florianópolis, em Santa Catarina? Assim, o objetivo geral do estudo é avaliar a situação de marketing do setor de vídeo locadoras na região Grande Florianópolis, em Santa Catarina. Os objetivos específicos são: identificar o perfil das vídeo locadoras que atuam na região; verificar a situação do ambiente interno de marketing, incluindo pontos fortes e fracos das organizações do setor, e o desempenho competitivo em relação à concorrência local;verificar a situação do ambiente externo de marketing, especificamente as ameaças e oportunidades de mercado. Esta pesquisa pode contribuir para ampliar os conhecimentos sobre a situação de marketing do setor de vídeo locadoras na região Grande Florianópolis/SC e fomentar a realização de estudos sobre diagnóstico mercadológico no contexto setorial.

\section{REFERENCIAL TEÓRICO}

Esta seção situa o presente estudo dentro da sua área de pesquisa e aborda os seguintes tópicos: fundamentos de diagnóstico mercadológico, modelos de elaboração de diagnóstico mercadológico e características do setor de vídeo locadoras no Brasil. 


\subsection{FUNDAMENTOS DE DIAGNÓSTICO MERCADOLÓGICO}

Grave e Seixas (1998) definem diagnóstico organizacional como ferramenta de construção do conhecimento sobre determinada organização, algo que possibilita avaliar o desempenho e decidir sobre objetivos e estratégias. Schneider e Machado (2008) definem esse diagnóstico como um processo de investigação sobre a organização e seu mercado, com o intuito de fazer prognósticos e apoiar a tomada de decisão. No passado, Morgan (1996) o classificou como tentativa de discernir o caráter da situação da organização.

No contexto de marketing, o diagnóstico mercadológico (diagnóstico de marketing ou análise da situação de marketing) é definido como o exame sistemático e detalhado de fatores externos e internos que afetam o desempenho de marketing da organização em dado período de tempo (McDONALD, 2006; WESTWOOD, 2006; HUDSON, 2010; SARQUIS; PIZZINATTO, 2013). Para Westwood (2006), esse diagnóstico é um instrumento de análisedos aspectos relevantes da empresa, incluindo vendas, estoques, custos, estratégias e posicionamento mercadológico, e que seu principal objetivo é identificar as dificuldades e oportunidades mais importantes.

Radulescu e Cetina (2012) apontaram que o diagnóstico mercadológico é um componente importante no planejamento de marketing, pois as decisões estratégicas devem ser baseadas em fatos/evidências da situação da organização. Ciente disso, no modelo de Pizzinatto e Silva (2009), a primeira etapa do processo de planejamento de marketing é a elaboração do diagnóstico mercadológico.D e forma resumida, Hooley, Saunders e Piercy (2012) afirmaram que o diagnóstico mercadológico visa a analisar o que a organização está fazendo, o que está acontecendo no ambiente da organização, e o que a organização poderia estar fazendo.

De acordo com Ritter et al. (2009), planejar estrategicamente não significa fazer premonições, mas agir de acordo com as possibilidades, tomar decisões exequíveis e aproveitar os fatores externos e internos favoráveis à organização. Além disso, quando não há foco na estratégia, os gestores tendem a focalizar em questões operacionais e os problemas estratégicos ficam difíceis de resolução (ARAÚJO, 1975). Assim, o diagnóstico mercadológico é essencial, e permite direcionar a atenção dos gestores para os problemas 
DIAGNÓSTICO MERCADOLÓGICO NO SETOR DE VIDEO LOCADORAS: ESTUDO NA GRANDE FLORIANÓPOLIS/SC Aléssio Bessa Sarquis - Mara C. Kich - Edson Roberto Scharf - Karina R. Wagner - Lenoir Hoeckesfeld

estratégicos, tomar decisões com base em fatos e conhecer a situação da organização.Sarquis e Pizzinatto (2012) sugerem que um diagnóstico mercadológico pode ser realizado para apoiar decisões sobre definição do negócio; para facilitar a seleção de mercados-alvo e a determinação de estratégias de marketing; para avaliar os problemas de desempenho no ambiente geral ou de estratégias específicas.De fato, um diagnóstico mercadológico pode, também,ser realizado para avaliar o nível de satisfação dos clientes e identificar as variáveis relevantes na avaliação dos clientes (RADONS; TORRES; CERETTA, 2013).

Em geral, o diagnóstico mercadológico requer uma avaliação do ambiente interno e externo da organização. Araújo (1975) e Schneider e Machado (2007) afirmam que o diagnóstico deve compreender a avaliação das variáveis relevantes da organização e do mercado, identificando os pontos fortes e fracos da organização. Campomar e Ikeda (2006) afirmaram, também, que é necessário identificar as situações favoráveis e desfavoráveis do ambiente externo, e as ameaças e oportunidades de mercado. Sarquis e Pizzinatto (2013) entendem que o processo de diagnóstico mercadológico deve envolver a avaliação da situação interna da organização, do mercado setorial, de clientes/segmentos, de concorrentes e de outras variáveis ambientais relevantes. Exemplos de variáveis ambientais relevantes são: excesso de impostos, escassez de financiamento, falta de políticas públicas, poder de negociação, ineficiência gerencial, cultura organizacional, disponibilidade de informações e capacidade financeira da organização (HOOLEY; PIERCY; NICOULAUD, 2012; SARQUIS; PIZZINATTO, 2013).

Conforme o objetivo estabelecido, algumas metodologias/técnicas de análise podem ser utilizadas no processo de diagnóstico mercadológico. Exemplos são: sistema de informações de marketing (MALHOTRA, 2008), Matriz Crescimento Mercados-Produtos (ANSOFF, 1965), Matriz GE/McKinsey (HAX; MAJLUF, 1984), Modelo de Estratégias Competitivas (PORTER, 2008), Curva de Classificação ABC (WYCKOFF, 1984), Técnicas de Previsão de Vendas (GEORGOFF; MURDICK, 1986) e Quadros de Cenários (GODET, 2000).

O estudo de Cancellier, Pellizzaro e Barbosa(2011) contém um diagnóstico mercadológico de canais de vendas/distribuição no contexto de serviços hoteleiros. 0 diagnóstico feito em uma organização de pequeno porte revelou as vantagens e Revista Eletrônica de Estratégia \& Negócios, Florianópolis, v.9, n.1, jan./abr. 2016. 
desvantagens de cada modalidade de canal de distribuição (direto e indireto); que quanto maior a quantidade de canais, maior a possibilidade de negócios; que os canais diretos mais utilizados são contato pessoal na recepção, website da empresa e central de reservas por telefone, e que os canais indiretos mais utilizados são agências de viagens, operadoras, profissionais autônomos e agências online.

De Sousa et al. (2015) investigaram os antecedentes na análise de desempenho no contexto de negócios e-business, a partir de revisão bibliográfica das principais abordagens teóricas subjacentes. Os resultados revelaram que os negócios e-business foram analisados sob o enfoque do ambiente externo e interno, mas que há, ainda, lacunas de pesquisa a serem estudadas (ex.: falta de escala validada para esse modelo de negócio; ausência de estudos quantitativos dos elementos que compõem o modelo de negócio; carência de estudos que analisem simultaneamente antecedentes e desempenho do modelo de negócio). Exemplos de antecedentes do desempenho relacionados ao ambiente externo são: contexto organizacional, contexto tecnológico e contexto ambiental. Exemplos de antecedentes ligados ao ambiente interno: parcerias estabelecidas, capacidades da organização, configuração de valor, proposta de valor, relacionamento com clientes e canais de distribuição (DE SOUSA et al., 2015).

\subsection{MODELOS DE DIAGNÓSTICO MERCADOLÓGICO}

O diagnóstico mercadológico requer um método de avaliação dos elementos (fatores/variáveis) que afetam o desempenho de marketing da organização (SARQUIS; PIZZINATTO, 2012). Na literatura de Administração e Marketing há algumas propostas de modelos de elaboração de diagnóstico mercadológico. De acordo com Campomar e Ikeda (2006), em nível internacional o modelo mais citado é o SWOT, estruturado por Andrews (1971).

No modelo SWOT (strengths, weaknesses, opportunities e threats), o processo de elaboração de diagnóstico mercadológico compreende a análise da situação da organização por meio da determinação de pontos fortes e pontos fracos (análise do ambiente interno), e da identificação de oportunidades e ameaças de mercado (análise do ambiente externo). Ponto forte é um ativo ou característica da organização que gera vantagem competitiva ou 
facilita o atingimento de objetivos de marketing. Ponto fraco é um ativo ou característica da organização que gera desvantagem competitiva ou dificulta o atingimento de objetivos de marketing. Oportunidade é uma situação do ambiente externo que pode contribuir para o atingimento dos objetivos de marketing ou para a melhoria da posição competitiva da organização. Enquanto a ameaça é uma situação do ambiente externo que gera perigo ou dificuldade para os objetivos de marketing ou para a posição competitiva da organização (ANDREWS, 1971; CAMPOMAR; IKEDA, 2006).

Galvão e De Sousa Melo (2008) aplicaram o modelo SWOT na análise da situação de marketing de um empreendimento turístico (ponto turístico) e revelaram que o modelo possibilitoua adequada avaliação da situação/realidade (incluindo características, infraestrutura e atrativos turísticos do empreendimento), e a obtenção de diagnóstico sobre o nível de desenvolvimento turístico da localidade. Segundo os autores, o modelo possibilitou, também, a elaboração de cenário do ambiente interno (forças e fraquezas) e do ambiente externo (oportunidades e ameaças) do ponto turístico analisado.

No âmbito nacional, o modelo de Campomar e Ikeda (2006)propõe que o processo de elaboração de diagnóstico mercadológico compreende 4 etapas: execução da análise interna; execução da análise externa; determinação das situações favoráveis e desfavoráveis do mercado e dos pontos fortes e fracos da organização; identificação das ameaças e oportunidades de mercado. A análise interna compreende a avaliação das características e políticas da organização, dos produtos/serviços e do programa de marketing. A análise externa consiste na avaliação de clientes/usuários, do setor/indústria da organização, da concorrência e demais condições ambientais. Uma situação favorável do ambiente é aquela que causa benefícios à organização; enquanto a situação desfavorável é aquela que lhe causa prejuízos/danos. O modelo proposto estabelece que a ameaça de mercado é resultado do encontro de situação desfavorável com ponto fraco, e que a oportunidade de mercado é resultado da junção de situação favorável com ponto forte da organização.

Sarquis e Pizzinatto (2012; 2013) propuseram um modelo conceitual de elaboração de diagnóstico mercadológico para organizações de serviços e de pequeno porte. O modelo proposto contém 5 etapas, descritas de forma detalhada e em sequência lógica de aplicação: preparação do diagnóstico; coleta de dados; preparação da análise; execução da análise; Revista Eletrônica de Estratégia \& Negócios, Florianópolis, v.9, n.1, jan./abr. 2016. 
sistematização dos resultados. A preparação do diagnóstico compreende a definição dos responsáveis, o entendimento da visão/missão da organização e a definição da finalidade, amplitude e abrangência do diagnóstico. A coleta de dados envolve a determinação dos fatores/variáveis relevantes, a identificação das fontes de informações e a execução da coleta de dados. A preparação da análise compreende a verificação dos dados coletados e a elaboração de materiais de análise sobre concorrência, clientes e demais aspectos do ambiente. A execução da análise compreende avalidação e avaliação dos fatores que afetam o desempenho de marketing da organização. A sintetização dos resultados inclui a descrição dos resultados e do relatório final.

Sarquis et al. (2012) testaram a aplicação do modelo teórico de Sarquis e Pizzinatto (2012; 2013) em uma organização familiar de pequeno porte, do setor de serviços. Os resultados revelam que o modelo teórico tem bastante aderência ao setor de serviços, tendo sido aplicadas 22 das 30 atividades (73\%) propostas. As atividades não aplicadas (ou apenas parcialmente aplicadas) foram: entendimento sobre missão/visão da organização; elaboração de material de análise sobre aspectos gerais do ambiente externo, mercado/setor e concorrência; avaliação de clientes/segmentos, concorrência e aplicação da análise SWOT; na sintetização dos resultados, a descrição sobre premissas do ambiente externo, clientes/segmentos atraentes, principais potencialidades e vulnerabilidades de marketing, oportunidades e ameaças de mercado mais relevantes.

\subsection{CARACTERÍSTICAS DO SETOR DE VÍDEO LOCADORAS NO BRASIL}

O setor de vídeo locadoras é composto por um conjunto de organizações (distribuidores e varejistas, com lojas físicas e online) que vendem e/ou alugam filmes, em formatos VHS, DVD e/ou Blu-ray (ALVES; DIAS; NOGUEIRA, 2010). Este setor atua no mercado de locação de vídeosou homevideo entertainment (FREITAS, 2004). No Brasil, o setor de vídeo locadoras cresceu a partir da década de 70, com o lançamento do videocassete e a proliferação de filmes em formatos VHS (SACRINI, 2005; VICENTINI; DOMINGUES, 2008). Segundo Anacleto e Michel (2008), no Brasil, as vídeo locadoras desenvolveram-se a partir da consolidação do cinema nacional e com a chegada de grandes estúdios de cinema. Contribuiu, também, a inexistência de salas de cinemas na maioria dos municípios brasileiros.Em 2008, o Brasil era o quinto maior mercado mundial de filmes em Revista Eletrônica de Estratégia \& Negócios, Florianópolis, v.9, n.1, jan./abr. 2016. 
VHS, DVD e Blu-ray, e a maioria das vídeo locadoras existentes era constituída de pequenas empresas, de propriedade familiar(ANACLETO; MICHEL, 2008).

Com o passar do tempo, alguns novos fatores gerar ameaças de mercado e passaram a comprometer a sobrevivência do setor de vídeo locadoras. Um dos principais fatores é a pirataria de filmes, que levou à redução no preço de locação e prejudicou a lucratividade das vídeo locadoras. Em 2004, no Brasil,a pirataria de filmes correspondia a 33,3\% do mercado e,em 2011, atingiu 52\% do mercado (SACRINI 2005; FECOMÉRCIO-RJ, 2012). Ballerini (2012) também apontou que a pirataria digital (download de filmes pela Internet sem autorização) tem prejudicado, em nível mundial, o mercado das vídeo locadoras e a indústria cinematográfica. Em 2014, o Brasil atingiu o quarto lugar entre os países que mais pirateiam filmes pela Internet (OLHAR DIGITAL, 2014). Outra ameaça de mercado relevante é a redução no preço da TV por assinatura, um serviço que oferece ao consumidor comodidade, qualidade de imagem e boa variedade de filmes (FREITAS, 2004; SACRINI, 2005). Segundo Silva, Lopes e Oliveira (2013), a falta de tempo dos consumidores é, também, outra ameaça de mercado. Os clientes possuem, hoje,um tempo curto para lazer e preferem assistir filmes pela Internet ou pela TV por assinatura (BALLERINI, 2012).

Os stakeholders do setor podem contribuir para a superação dessas ameaças de mercado. Stakeholders podem apoiar no fortalecer do setor de vídeo locadoras, transformando as organizações mais resistentes e elevando a proposta de valor do negócio(SILVA; LOPES; OLIVEIRA, 2013). Na opinião de Ballerini (2012), os proprietários de vídeo locadoras têm papel fundamental na superação dessas ameaças de mercado. Eles podem oferecer novos produtos/serviços aos clientes e investir na diversificação do negócio. As vídeo locadoras podem atuar, também, como lan house, locação de games, venda de produtos de conveniência, fotocópias, venda de livros, locação virtual e sorveteria, por exemplo. Bieging e Aquino (2014) recomendam,ainda, a intensificação dos investimentos em marketing, especialmente na divulgação de lançamentos e no estímulo à comunicação boca a boca, ou ao marketing viral. Alves, Dias e Nogueira (2010) recomendam investimentos em estratégias de relacionamento e retenção de clientes. 


\section{ASPECTOS METODOLÓGICOS}

O estudo foi realizado em duas etapas e classificado conforme propõem Creswell e Clark (2007) e Johnson, Onwuegbuzie e Turner (2007). A etapa 1 envolveu a realização de pesquisa exploratória, qualitativa e de abordagem direta ao entrevistado (não disfarçada). A etapa 2compreendeu a aplicação de pesquisa descritiva, quantitativa e na forma de levantamento de campo, com corte transversal (survey cross-sectional). A pesquisa exploratório-qualitativa (etapa 1) foi necessária para ampliar o conhecimento dos pesquisadores sobre o problema investigado (situação de marketing do setor de vídeo locadoras) e para apoiar na preparação do levantamento de campo (etapa 2). A pesquisa descritivo-quantitativa foi empregada para dimensionar o perfil das vídeo locadoras da regiãoGrande Florianópolis, em Santa Catarina,e a situação de marketing do setor, na opinião dos proprietários/gestores pesquisados.

A população do estudo foi composta pelas vídeo locadoras atuantes na região da Grande Florianópolis, em Santa Catarina, especificamente nos municípios de Florianópolis, Palhoça, São José e Biguaçu (total de 48 vídeo locadoras). A relação das vídeo locadoras atuantes foi obtida a partir de informações de uma das principais distribuidoras de vídeo/DVD na região (Visocopy). Na etapa 1, a amostra foi constituída por 1 proprietário de vídeo locadora, selecionado por julgamento considerando tempo de atuação no setor (mais de 10 anos) e bom conhecimento da região da Grande Florianópolis/SC. Na etapa 2, a amostra foi composta por 26videolocadoras, selecionadas por conveniência, aquelas que aceitaram espontaneamente participar do estudo no período da coleta de dados.

Quanto ao método de coleta, na etapa 1, a entrevista pessoal em profundidade (DENZIN; LINCOLN, 2009) foi aplicada de forma fracionada (em 2 etapas), com gravação de áudio e apoiada por roteiro de entrevista (previamente validado), contendo perguntas sobre ambiente interno de marketing, ambiente externo de marketing e características dos consumidores. A entrevista teve duração média de $2 \mathrm{~h} 30$ minutos. Na etapa 2, o método questionário auto administrado foi utilizado e aplicado pessoalmente nas instalações das vídeo locadoras e pela Internet, na plataforma Google Docs, e acompanhado de carta convite aos pesquisados. O questionário aplicado contém perguntas sobre perfil das vídeo locadoras, desempenho das vídeo locadoras em relação à concorrência, pontos fortes/fracos Revista Eletrônica de Estratégia \& Negócios, Florianópolis, v.9, n.1, jan./abr. 2016. 
das vídeo locadoras e oportunidades/ameaças de mercado. Ambos os instrumentos de coleta foram elaborados a partir do modelo de diagnóstico mercadológico proposto por Sarquis et al. (2012), Sarquis e Pizzinatto (2012; 2013). Os critérios de desempenho competitivo foram baseados em Hooley, Piercy e Nicoulaud (2012). A coleta de dados ocorreu no período de janeiro e março/2015.

Quanto ao método de análise, a pesquisa quantitativa envolveu a aplicação de técnicas estatísticas descritivas, incluindo frequência absoluta, frequência relativa, média aritmética, desvio padrão e a mediana, conforme a escala da variável de pesquisa mensurada. O software Microsoft Excel ${ }^{\mathrm{TM}} 2013$ foi utilizado no tratamento e na análise estatística dos resultados.

\section{APRESENTAÇÃO E ANÁLISE DOS RESULTADOS}

Esta seção apresenta os resultados da pesquisa quantitativa (etapa 2). Os resultados da pesquisa qualitativa (etapa 1) não serão apresentados e serviram apenas para ampliar o conhecimento dos pesquisadores sobre o problema investigado e para apoiar na preparação da pesquisa quantitativa.Abaixo contém a descrição do perfil das vídeo locadoras pesquisadas, os resultados da situação do ambiente interno de marketing e os resultados da situação do ambiente externo de marketing.

\subsection{PERFIL DAS VÍDEO LOCADORAS PESQUISADAS}

A Tabela 1 apresenta os resultados do perfil da amostra do presente estudo, com relação à localização da loja (município da Grande Florianópolis/SC), tempo de existência (em anos), quantidade de funcionários (incluindo proprietários) e percentual do faturamento investido em marketing no ano de 2014.

Do total de vídeo locadoras participantes do estudo, 39,1\% delas estão localizadas em Florianópolis/SC, 39,1\% em Palhoça, 13\% em São José e 4,3\% em Biguaçu (4 vídeo locadoras não revelaram sua localização). Em média, as vídeo locadoras participantes do estudo têm 12 anos de existência, e as localizadas em Florianópolis têm 14,8 anos, em Palhoça 12,2 anos, em São José 7,3 anos e em Biguaçu 8 anos. Em termos de quantidade de funcionários, as vídeo locadoras pesquisadas têm em média 2,2 funcionários, e as de 
Florianópolis têm 2,3 funcionários, de Palhoça 2,4 funcionários, de São José 1,7 funcionários e de Biguaçu 2 funcionários. Em termos de percentual de investimento em marketing, no ano de 2014 as vídeo locadoras pesquisadas investiram em média 7,9\% do faturamento anual em ações de marketing/vendas, e as localizadas em Florianópolis investiram 6,2\%, em Palhoça 8,8\%, em São José 5\% e Biguaçu 12\%.

Tabela 1- Perfil da amostra $(n=22)$

\begin{tabular}{l|c|c|c|c|c}
\hline ITEM & FLORIANÓPOLIS & PALHOÇA & SÃO JOSÉ & BIGUAÇU & TOTAL \\
\hline Localização & & & & & \\
* Contagem & 9 & 9 & 3 & 1 & 22 \\
* Percentual (\%) & 39,1 & 39,1 & 13,0 & 4,3 & 100,0 \\
Tempo de existência & 14,8 & 12,2 & 7,3 & 8,0 & 12,0 \\
* Média & 5,9 & 6,8 & 3,8 & 0,0 & 6,2 \\
* Desvio padrão & & & & & \\
Quantidade de funcionários & 2,3 & 2,4 & 1,7 & 2,0 & 2,2 \\
* Média & 1,0 & 0,7 & 0,6 & 0,0 & 0,9 \\
* Desvio padrão & & & & & \\
Percentual investido em marketing/2014 & 6,2 & 8,8 & 5,0 & 12,0 & 7,9 \\
* Média & 6,9 & 10,5 & 0,0 & 0,0 & 8,5 \\
* Desvio padrão &
\end{tabular}

Fonte: Dados da pesquisa (2015).

O Gráfico 1 mostra os principais serviços oferecidos pelas vídeo locadoras pesquisadas. Os resultados revelam que pelo menos metade delas oferecem os serviços: locação de Blu-ray (100\% delas), locação de DVD (96,2\%), venda de DVD (65,4\%), recarga de celular $(53,8 \%)$ e venda de produtos conveniência, incluindo chocolates, pipoca e outros alimentos (50\%). Algo que merece destaque são os serviços novos oferecidos por pelo menos 1/4 das vídeo locadoras pesquisadas, quais sejam:venda de bebidas (46,2\%), venda de Blu-ray (38,5\%), impressão/cópias (34,6\%) e locação de vídeo games, como Play Station 3 $(30,8 \%)$. Embora em minoria, algumas vídeo locadoras revelaram também oferecer os serviços de venda de cosméticos, roupas e bijuterias. 
Gráfico 1 - Principais serviços oferecidos pelas vídeo locadoras pesquisadas ( $n=26$ )

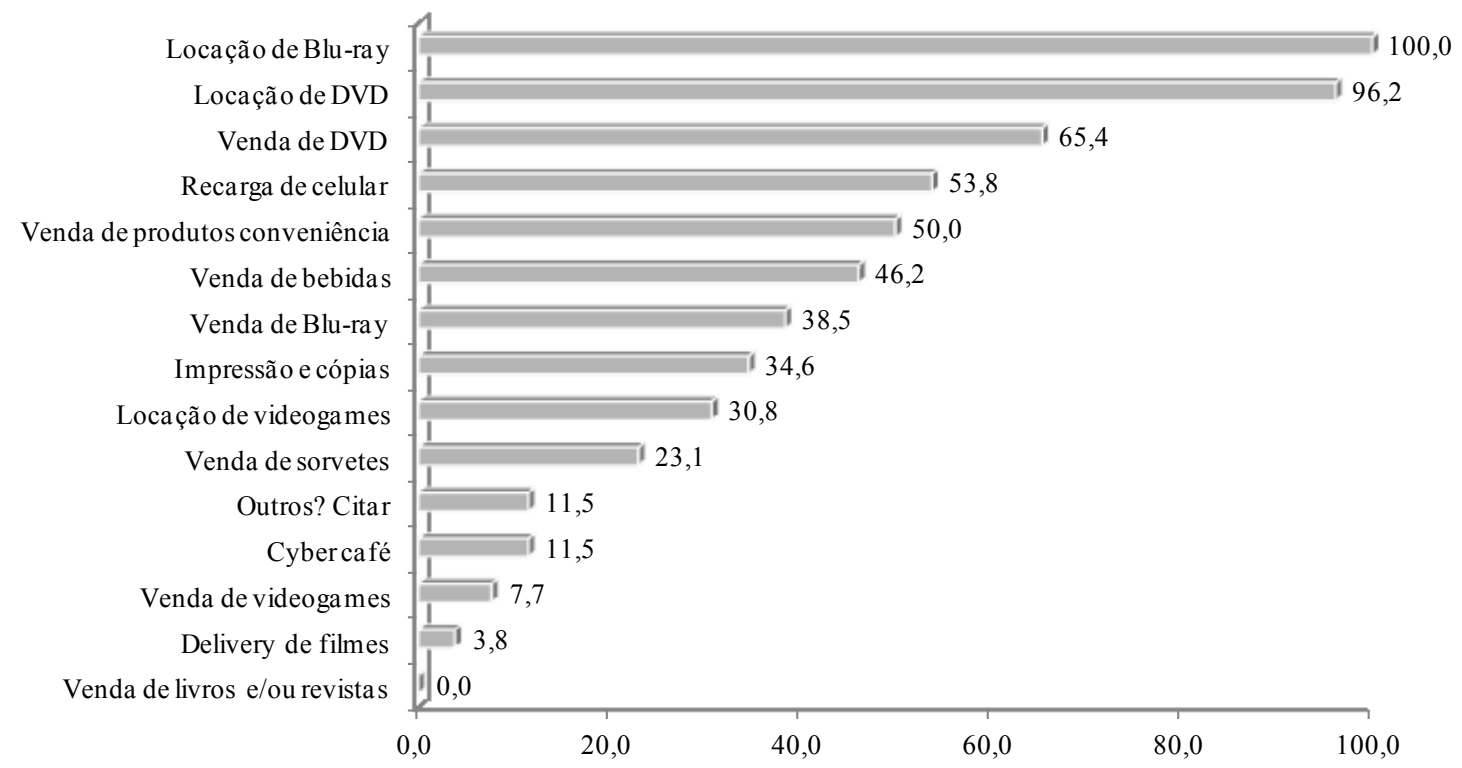

Fonte: Dados da pesquisa (2015).

Diante dos dados coletados, pode-se afirmar que o perfil das vídeo locadoras pesquisadas na região Grande Florianópolis/SC é predominantemente constituído por organizações localizadas em Florianópolis e Palhoça;organizações que têm em média 13,5 anos de existência, 2,4 funcionários (incluindo proprietários) e que oferecem os serviços de locação de Blu-ray, locação de DVD, venda de DVD, recarga de celular e venda de produtos conveniência; organizações que, em 2014, investiram em marketing o equivalente a 7,5\% do faturamento anual.

\subsection{SITUAÇÃO DO AMBIENTE INTERNO DE MARKETING}

Um dos objetivos do presente estudo é verificar a situação do ambiente interno de marketing do setor de vídeo locadoras na região Grande Florianópolis/SC. Para isso, a coleta de dados buscou identificar os pontos fortes e fracos das organizações do setor, e o desempenho competitivo em relação à concorrência local. Em escala Likert de 5 pontos, os pesquisados analisaram uma lista de 24 aspectos relacionados a competências, recursos e estratégias de marketing que podem representar ponto forte (qualidade, vantagem) ou ponto fraco (deficiência, vulnerabilidade) das organizações do setor de vídeo locadoras na região Grande Florianópolis/SC.

Revista Eletrônica de Estratégia \& Negócios, Florianópolis, v.9, n.1, jan./abr. 2016. 
O Gráfico 2 apresenta os resultados de pontos fortes e fracos das organizações do setor, incluindo a média aritmética, o desvio padrão e o somatório dos percentuais das escalas 4 e 5 . Os resultados do total da amostra $(n=26)$ indicam que, na opinião da maioria dos pesquisados, os principais pontos fortes do setor são por ordem decrescente: forma de atendimento/atenção aos clientes (100\%), acervo de filmes e lançamentos (96\%), preço de vendas/locação de filmes (91,7\%), localização/visibilidade da loja (80\%), perfil/comprometimento dos funcionários (80\%), conhecimento de custos/rentabilidade da organização (79,2\%), relacionamento com fornecedores/parceiros comerciais (76\%), estratégias de promoção/descontos (76\%), sucesso na compra de novos filmes (76\%), satisfação/fidelização dos clientes (72\%), conhecimento sobre mercado/concorrência (60\%) e instalações/formato da loja (53,8\%). Ao passo que os principais pontos fracos são: marketing pela Internet (41,7\%), conhecimento/competência em marketing (36\%), propaganda da marca $(20,8 \%)$ e recursos para investimento em marketing $(20,8)$. Observa-se que os pontos fracos apontados são predominantemente aspectos relacionados ao processo de comunicação de marketing das organizações, confirmando os resultados dos estudos de Sarquis (2003) e Pereira et al. (2009), que apontaram deficiências nesta prática de marketing de pequenas empresas.

Gráfico 2 - Pontos fortes e fracos do setor de vídeo locadoras $(n=26)$

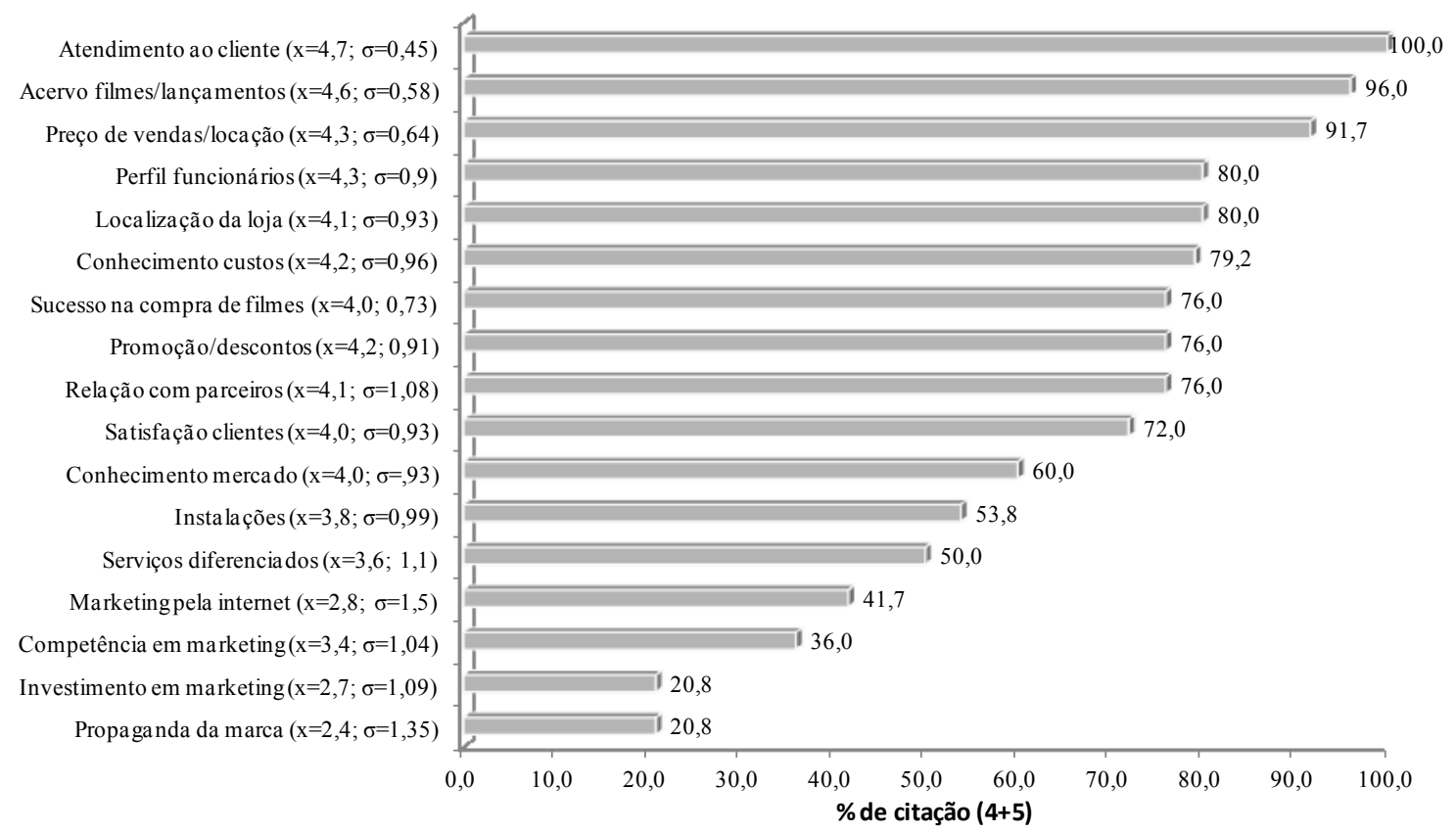

Revista Eletrônica de Estratégia \& Negócios, Florianópolis, v.9, n.1, jan./abr. 2016. 
Fonte: Dados da pesquisa (2015).

Em termos de média aritmética, os resultados do Gráfico 2 mostram intensidade de pontos fortes e fracos semelhante às apontadas na análise de frequência. As médias aritméticas também são menores nos aspectos (competências, recursos e estratégias) com menor frequência de citação, ou seja: marketing pela Internet, conhecimento/competência em marketing, propaganda da marca e recursos para investimento em marketing. Com relação ao desvio padrão, a maioria das variáveis/aspectos mensurados apresenta baixa dispersão dos valores em relação à média (inferior a $20 \%$ da escala aplicada, como recomendam Hair et al., 2009), indicando opiniões relativamente homogêneas e consistência dos resultados. As poucas variáveis com desvio padrão elevado são aquelas que apresentam menor média aritmética e frequência de citação (Propaganda da marca e Marketing pela Internet).

O Gráfico 3 apresenta os resultados de desempenho competitivo das vídeo locadoras em relação à concorrência local, cuja amostra variou de 14 a 25 participantes. Cada vídeo locadora pesquisada avaliou o seu desempenho competitivo com base em 6 critérios de competitividade definidos a partirde Hooley, Piercy e Nicoulaud (2012): satisfação dos clientes, lealdade dos clientes, qualidade dos serviços/atendimento, valor de vendas/faturamento, participação de mercado e rentabilidade (ou margem obtida nos preços).

Gráfico 3 - Desempenho competitivo das vídeo locadoras em relação à concorrência local 


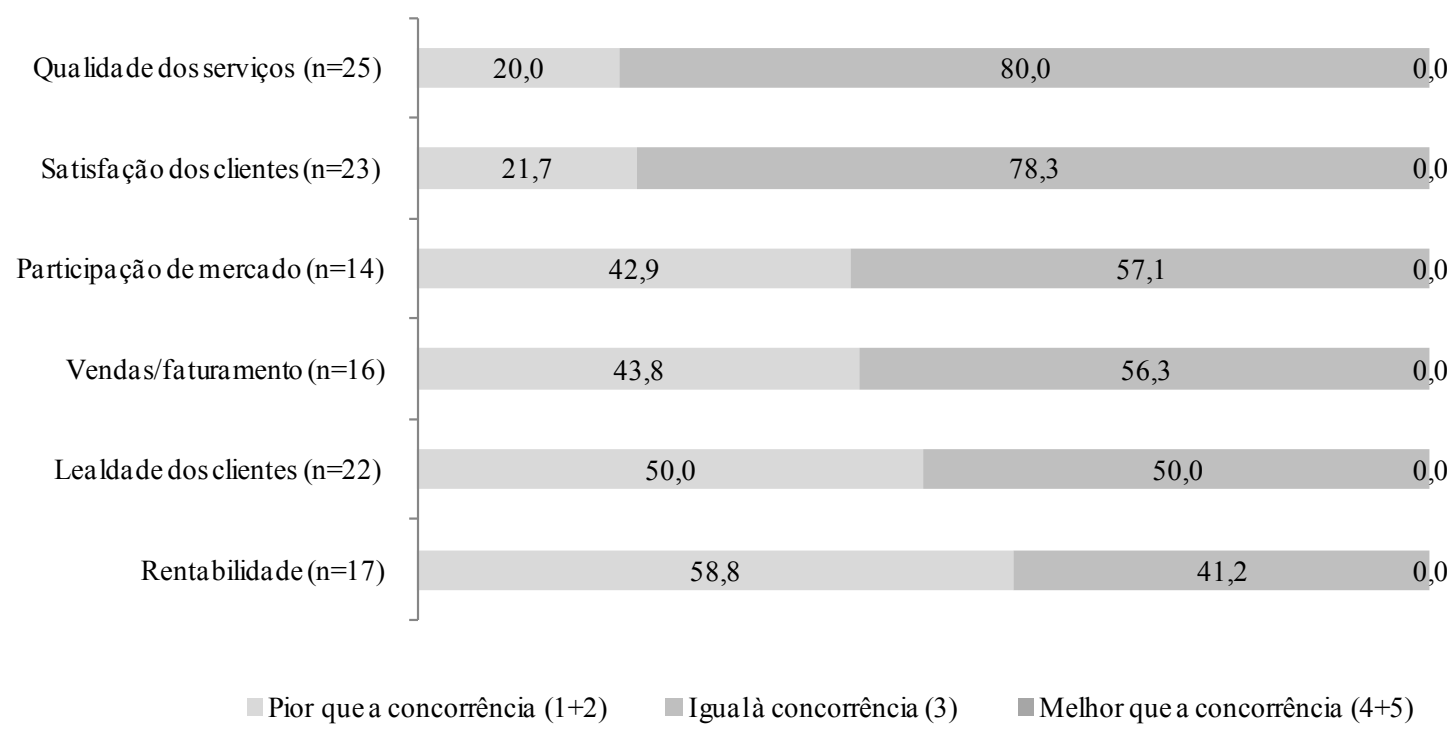

Fonte: Dados da pesquisa (2015).

Os resultados do Gráfico 3 mostram que nenhuma das vídeo locadoras pesquisadas tem desempenho competitivo melhor que a concorrência local, em qualquer dos critérios competitivos analisados. De fato, a maioria delas afirma ter desempenho competitivo igual à concorrência na maior parte dos critérios competitivos avaliados: qualidade dos serviços/atendimento (80\%), satisfação dos clientes $(78,3 \%)$, participação de mercado $(57,1 \%)$ e valor de vendas/faturamento (56,3\%). Cabe destacar, no entanto, que há um percentual significativo de vídeo locadoras (mais de $1 / 3$ dos pesquisados) que avaliam ter desempenho competitivo pior que a concorrência local em pelo menos 4 dos critérios analisados: rentabilidade (58,8\%), lealdade dos clientes $(50 \%)$, valor de vendas/faturamento(43,8\%) e participação de mercado (42,9\%).Conforme Silva, Lopes e Oliveria (2013), este quadro de deficiências deve ser reflexo da crise que o setor tem passado ao longo da última década, com redução na demanda por locação de filmes, no volume de vendas, na quantidade de clientes e com a falência de inúmeras vídeo locadoras. Os resultados indicam, também, que as vídeo locadoras estão investindo mais na qualidade dos serviços/atendimento e na satisfação dos clientes como estratégicas de marketing para enfrentaras dificuldades do setor.

\subsection{SITUAÇÃO DO AMBIENTE EXTERNO DE MARKETING}

O último objetivo do estudo é verificar a situação do ambiente externo de marketing das organizações do setor de vídeo locadoras da região Grande Florianópolis/SC, Revista Eletrônica de Estratégia \& Negócios, Florianópolis, v.9, n.1, jan./abr. 2016. 
incluindo as principais ameaças e oportunidades de mercado. O Gráfico 4 apresenta os resultados de fatores de ameaça de mercado apontados pelas vídeo locadoras pesquisadas $(n=26)$. As ameaças de mercado assinaladas por pelo menos $2 / 3$ das pesquisadas são: download gratuito de filmes pela Internet (96,2\% delas), intensidade da pirataria $(80,8 \%)$, popularização da televisão por assinatura (65,4\%), Internet como opção de lazer, como as redes sociais $(50 \%)$, redução na demanda dos consumidores $(38,5 \%)$ e existência de locadoras virtuais, como Netflix, Netmovies, Saraiva Digital e Sunday TV (34,6\%). Assim, conforme definição de Sarquis e Pizzinatto (2012), esses são fatores desfavoráveis do ambiente externo que causam perigo, problema e/ou dificuldade no desempenho de marketing das vídeo locadoras da região Grande Florianópolis/SC.

Os fatores de ameaças de mercado menos apontados pelas vídeo locadoras pesquisadas são: forma de comercialização dos distribuidores, baixo poder aquisitivo dos consumidores, uso de vídeo games pelo consumidor, preço praticado pela concorrência, situação econômica da região e a forma de atuação da concorrência local. Em outros fatores foram mencionados também aspectos como: falta de tempo dos consumidores, consumidor que aceita produto de baixa qualidade, inadimplência dos consumidores, falta de fiscalização do governo e preço praticado pelas locadoras virtuais.

Gráfico 4 - Principais ameaças de mercado no setor de vídeo locadoras ( $n=26$ )

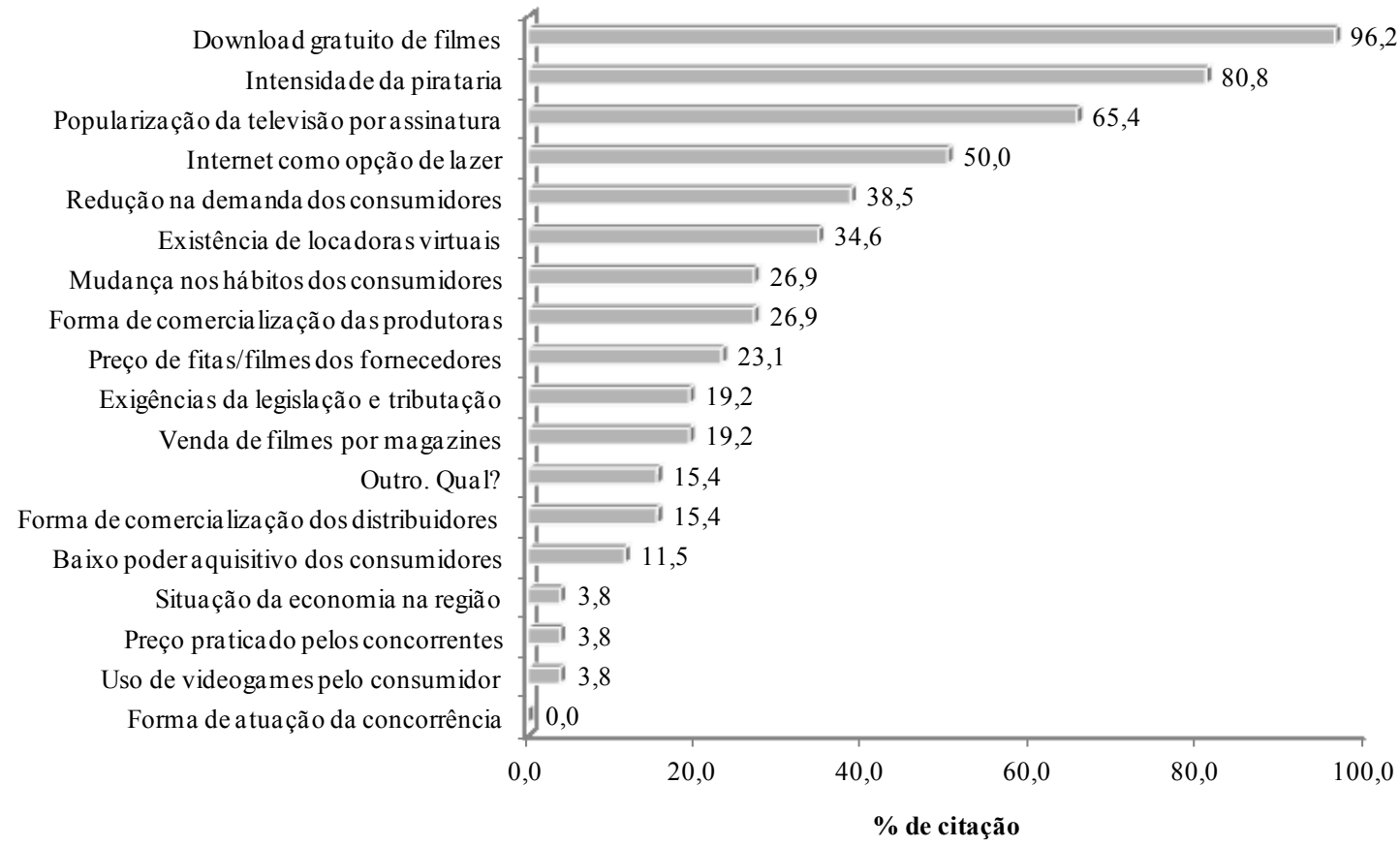

Revista Eletrônica de Estratégia \& Negócios, Florianópolis, v.9, n.1, jan./abr. 2016. 
Fonte: Dados da pesquisa (2015).

O Gráfico 5 apresenta os resultados de oportunidades de mercado para as organizações do setor de vídeo locadoras da região Grande Florianópolis/SC ( $n=26)$. As oportunidades de mercado assinaladas por pelo menos $2 / 3$ das pesquisadas são: relacionamento/fidelidade de clientes $(65,4 \%)$, oferta de promoções/descontos $(61,5 \%)$, parceria com fornecedores e distribuidores (50\%), diversificação de produtos, como venda de lanches, bebidas e sorvetes (38,5\%) e diversificação do negócio, como CyberCafé e Lan House $(34,6)$.Como definido por Sarquis e Pizzinatto (2012), esses são fatores favoráveis do ambiente externo,que podem contribuir para o alcance dos objetivos de marketing e/ou para melhora da posição competitiva das vídeo locadoras da região Grande Florianópolis/SC.

As oportunidades de mercado menos apontados pelas vídeo locadoras pesquisadas são: focalização em determinados clientes/nichos de mercado, especialização em determinados produtos (ex: Blu-ray, 3D), prestação de serviços de entrega em domicílio, utilização das novas tecnologias, oferta de serviço pela Internet (ex.: serviço de streaming e downloads), atuação em rede das vídeo locadoras, uso de eventos temáticos para atrair clientes, valorização na loja dos filmes nacionais, e a valorização de filmes musicais, clássicos ou de arte.

Gráfico 5 - Principais oportunidades de mercado no setor de vídeo locadoras ( $n=26$ ) 


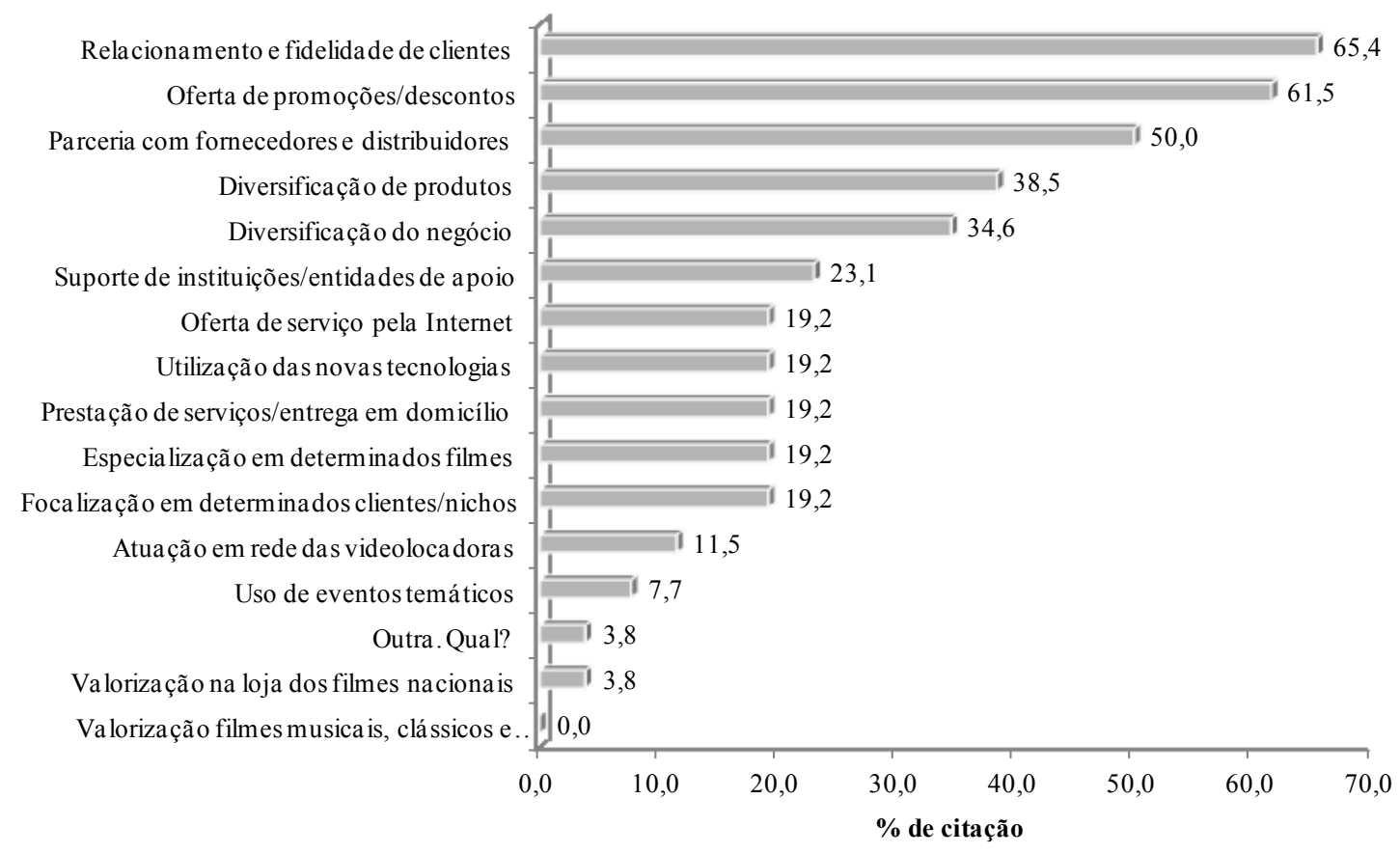

Fonte: Dados da pesquisa (2015).

\subsection{DISCUSSÃO DOS RESULTADOS}

Os resultados do presente estudo indicam que o setor de vídeo locadoras na região Grande Florianópolis/SC é constituído por organizações de pequeno porte (média 2,2 funcionários) e que atuam predominantemente na locação de filmes (mais de $90 \%$ deles oferecem locação de Blu-ray e DVD), como apontado por Freitas (2004). É também constituído por organizações de propriedade familiar, conforme revelou o estudo de Anacleto e Michel (2008). Os resultados apontaram, ainda, que o setor na Grande Florianópolis/SC está em declínio, tanto em termos de competitividade de mercado como na quantidade de organizações. Nenhuma das vídeo locadoras pesquisadas assinalou ter desempenho competitivo superior à concorrência, em quaisquer dos critérios competitivos analisados, e 43,8\% delas assinalaram ter desempenho inferior à concorrência no montante de vendas/faturamento. Além disso, na coleta de dados, quando do contato inicial por telefone para agendamento da entrevista, verificou-se que grande quantidade de vídeo locadoras já não existiam ou estavam em processo de falência.

Na região investigada, o setor de vídeo locadoras enfrenta graves ameaças de mercado, principalmente em decorrência de fatores relacionados ao avanço da Revista Eletrônica de Estratégia \& Negócios, Florianópolis, v.9, n.1, jan./abr. 2016. 
tecnologia/Internet (ex.: intensidade da pirataria, download gratuito de filmes pela Internet e surgimento de vídeo locadoras virtuais) e à mudança no comportamento dos consumidores (ex.: popularização da televisão por assinatura, uso da Internet e redes sociais como opção de lazer e redução na demanda dos consumidores). Esses resultados confirmam as proposições de Sacrini (2005) sobre o assunto, especificamente sobre o impacto da televisão por assinatura, e de Ballerini (2012) sobre a ameaça da oferta de filmes pela Internet e das vídeo locadoras virtuais. Tais fatores de mercado estão fora do controle das vídeo locadoras, e tendem a afetar o desempenho competitivo do setor, especialmente considerando que este é constituído por organizações de pequeno porte, com poucos recursos financeiros e limitadas competências em marketing.

Além das mencionadas ameaças de mercado, na região Grande Florianópolis/SC, o setor de vídeo locadoras tem deficiências de marketing em aspectos/práticas relevantes no mercado competitivo: conhecimento/competências em marketing, recursos financeiros para investimento, uso da Internet como ferramenta de marketing e ações de comunicação/propaganda. Os estudos de Sarquis (2003) e Pereira et al. (2009) identificaram, também, que essas deficiências estão presentes na prática de marketing de pequenas empresas de outros ramos de atividades (ex.: confecções de vestuários, turismo e entretenimento). No entanto, como apontado por Kamakura et al. (2002) e Tam (2004), essas estratégias de marketing podem contribuir para elevar a retenção de clientes e para melhorar a rentabilidade dos serviços. Diante disso, as vídeo locadoras pesquisadas precisam investir na qualidade dos serviços, no atendimento aos clientes, na oferta de novos produtos e na satisfação dos clientes. Segundo Sarquis (2009), no estágio de declínio de produtos ou setores, exemplos de estratégias de marketing recomendadas são o direcionamento das vendas para clientes mais atraentes, a manutenção do serviço apenas nas principais regiões/locais (ou mercados), a redução da margem e/ou despesas operacionais do serviço e a elevação do preço para melhorar a rentabilidade dos consumidores retardatários ou conservadores.

Outras estratégias recomendadas são aproveitar as oportunidades de mercado existentes, como o hábito do consumidor brasileiro de ser atraído por promoções/merchandising, a possibilidade de parcerias e ações cooperativadas com 
fornecedores e distribuidores de filmes, e a disponibilidade de associações empresariais e entidades de apoio, como a Câmara de Dirigentes Lojistas (CDL), sindicatos de lojistas, associação comercial e industrial e o Serviço Brasileiro de Apoio às Micro e Pequenas Empresas (SEBRAE), por exemplo.Conforme Silva, Lopes e Oliveira (2013), os stake holders podem contribuir para a sobrevivência das organizações do setor. Com o apoio do Sebrae, as vídeo locadoras da região podem, por exemplo, promover ações em conjunto de qualificação de gestores e funcionários, de avaliação detalhada da situação de mercado (mudanças, influências e tendências no comportamento dos consumidores) e de investimento em estratégias de marketing que possam atenuar as dificuldades e assegurar a sobrevivência do setor. Com o apoio da CDL, sindicatos de lojistas e da associação comercial e industrial, ações cooperativadas podem ser realizadas para elevar o poder de barganha/negociação das vídeo locadoras e para solucionar problemas e desafios comuns ao setor na Grande Florianópolis/SC, por exemplo.

Os resultados do estudo apontaram ainda que grande parte das vídeo locadoras pesquisadas está partindo para a diversificação do mix de produtos/serviços e/ou para a diversificação do negócio. Metade delas está oferecendo produtos de conveniência, incluindo chocolates, pipoca e outros alimentos no ambiente da loja. Pelo menos 1/4 delas está oferecendo também impressão/cópias e locação de vídeo games. Ferrell e Hartline (2011) afirmaram que a competitividade do negócio pode ser melhorada pela ampliação do mix de produtos e/ou diversificação do negócio. Os resultados apontam, ainda, que as vídeo locadoras estão investindo na melhoria do atendimento aos clientes, acervo de filmes/lançamentos, promoção de vendas/locação de filmes, instalações/formato da loja, perfil dos funcionários, relacionamento com fornecedores/parceiros comerciais e ações de satisfação/fidelização dos clientes. Tais fatores podem contribuir para a manutenção e sobrevivência das vídeo locadoras na região estudada.

\section{CONSIDERAÇÕES FINAIS}

Este estudo avaliou a situação de marketing do setor de vídeo locadoras na região Grande Florianópolis, em Santa Catarina. Para tanto, a pesquisa de campo coletou dados sobre o perfil das vídeo locadoras que atuam na região; os pontos fortes e fracos das 
organizações do setor, e o desempenho competitivo em relação à concorrência local; as ameaças e oportunidades de mercado. Estes objetivos do estudo foram alcançados.

Quanto ao perfil das vídeo locadoras, na região Grande Florianópolis/SCo setor é predominantemente constituído por organizações que têm em média 13,5 anos de existência, 2,4 funcionários e que oferecem serviços de locação de Blu-ray, locação de DVD, venda de DVD, recarga de celular e venda de produtos conveniência; organizações que investiram em 2014 o equivalente a 7,5\% do faturamento anual em ações de marketing/vendas.

Os principais pontos fortes das vídeo locadoras na Grande Florianópolis/SC são atendimento aos clientes, acervo de filmes/lançamentos, preço de vendas, perfil dos funcionários, conhecimento da organização, relacionamento com fornecedores/parceiros, satisfação dos clientes, conhecimento sobre mercado e as instalações da loja. Já os principais pontos fracos são pouco uso da Internet como ferramenta de marketing, pouco conhecimento/competência em marketing, propaganda da marca/loja e limitação de recursos para investimento em marketing. Um percentual significativo das vídeo locadoras pesquisadas revelou ter desempenho competitivo inferior à concorrência local na maioria dos critérios competitivos analisados.

As principais ameaças de mercado apontadas pelas vídeo locadoras pesquisadas são download gratuito de filmes pela internet, intensidade da pirataria, popularização da televisão por assinatura, uso da internet como opção de lazer pelos consumidores, redução na demanda dos consumidores e existência de locadoras virtuais. Enquanto as principais oportunidades de mercado apontadas são fidelização de clientes satisfeitos, intensificação de promoções/descontos, possibilidade de parcerias com fornecedores, distribuidores e entidades de apoio aos lojistas e possibilidade de diversificação de produtos e do negócio.

No âmbito acadêmico, este estudo contribuiu para ampliar o conhecimento sobre a situação de marketing das vídeo locadoras na região Grande Florianópolis/SC, um setor comercial ainda pouco estudado em nível nacional (ANACLETO; MICHEL, 2008) e que busca desenvolver esforços para enfrentar as graves ameaças de mercado (CDL, 2013). O trabalho contribuiu,também, para fomentar os estudos sobre diagnóstico mercadológico no contextos 
etorial envolvendo organizações de serviços e pequeno porte, uma necessidade apontada no estudo de Sarquis e Pizzinatto (2012). No âmbito gerencial, o estudo possibilitou a identificação de oportunidades de mercado e de estratégias de marketing recomendáveis para vídeo locadoras que desejam enfrentar as mencionadas dificuldades e mudanças de mercado. E contribuiu para fomentar a realização de estudos semelhantes em setores de atividade que estão em situação de declínio e para a identificação de oportunidades para futuros estudos sobre o tema.

Como direcionamento para futuros estudos acadêmicos sobre o tema, recomendase,inicialmente,a replicação do presente estudo em outras regiões do Estado de Santa Catarina e do Brasil; a realização de diagnósticos mercadológicos em outros setores ou ramos de atividade que estejam em situação de declínio ou com redução expressiva na quantidade de organizações ou no volume de vendas. Recomenda-se, também, a realização de estudos qualitativos, na forma de estudo de caso com entrevista em profundidade, para compreender melhor o desempenho e as estratégias de marketing utilizadas por vídeo locadoras que estão superando as adversidades do mercado, ou com desempenho competitivo superior à concorrência. Outra sugestão é a execução de pesquisa-espelho com consumidores/clientes de vídeo locadoras para confirmação dos dados/resultados do presente estudo.

\section{AGRADECIMENTO}

O presente estudo contou com o apoio do Programa de Bolsa de Pesquisa (Artigo 170) do Governo do Estado de Santa Catarina.

\section{REFERÊNCIAS}

ALVES. S.; DIAS. P.; NOGUEIRA. A. Netmovies: aluguel de filmes em tempos de pipoca virtual. Anais do 34을 Encontro da ENANPAD. Rio das Pedras/RJ, 2010.

ANACLETO, A.; MICHEL, S. Cinema e homevideo entertainmet: um estudo de marketing sobre o mercado da magia e a magia do mercado, 2008. Disponível em: <http://www.isepeguaratuba.com.br/inc/pdf/isepe_guaratuba_artigo003.pdf $>$. Acesso em: 27 mar. 2015.

ANDREWS, K. The concept of corporate strategy. Illinois: Dow Jones Irwin, 1971. 
ANSOFF, I. Corporate strategy: an analytic approach do business policy for growth and expansion. New York: McGraw-Hill, 1965.

ARAÚJO, L. Manual para diagnóstico de administração de empresas. Revista de Administração de Empresas, v. 15, n. 4, p. 73-73, 1975.

BALLERINI, F. Cinema brasileiro no século XXI. São Paulo: Summus Editorial, 2012.

BARDIN, L. Análise de conteúdo. Lisboa: Edições 70, 2008.

BIEGING, P.; AQUINO, V. A experiência estética no iCinema: sensação e interatividade a partir de narrativas multilineares. In: Patricia Bieging; Victor Aquino. (Org.). Olhares do sensível: experiências e dimensões estéticas em comunicação. São Paulo: Pimenta Cultural, 2014.

CAMPOMAR, M.; IKEDA, A. O planejamento de marketing e a confecção de planos: dos conceitos a um novo modelo. São Paulo: Saraiva, 2006.

CANCELLIER, L.; PELLIZZARO, E.; BARBOSA, F. Análise dos canais de distribuição em hotel de pequeno porte em Balneário Camburiú ( $\mathrm{SC}$ ). Revista Eletrônica de Estratégia \& Negócios, v. 4, n. 1, p. 3-18, 2011.

CDL, Câmara de Dirigentes Lojistas de Florianópolis.Ação em defesa das videolocadoras mobiliza segmento em todo o Brasil - 2013. Disponível em: <http://www.cdlfloripa.org.br/noticia/acao-em-defesa-das-videolocadoras-mobilizasegmento-em-todo-o-brasil-2392>. Acesso em: 10 mar 2016.

CRESWELL, J.; CLARK, V. Designing and conducting mixed methods research. New Jersey: John Wiley \& Sons, Inc, 2007.

DE MELLO, L.; KLIEMANN, A. A Indústria De Videogames Sob O Enfoque Do Modelo Delta. Anais do 34을 Encontro da ENANPAD. Rio das Pedras/RJ, 2010.

DE SOUZA, E.; BATISTA, P.; SANTIAGO, A.; CHAVES, B.; PINTO, F. Antecedentes estratégicos e modelo de negócios: uma proposta integrada de análise para o desempenho de e-business. Revista Eletrônica de Estratégia \& Negócios, v. 8, n. 2, p. 26-53, 2015.

DENZIN, N.; LINCOLN, Y. Qualitative research. Yogyakarta: Pustaka Pelajar, 2009.

FECOMÉRCIO RJ, Federação do Comércio do Estado do Rio de Janeiro. Pesquisa da Fecomércio-RJ/Ipsos sobre o consumo de produtos piratas no Brasil, 2012. Disponível em: $<$ http://www.fecomercio-

rj.org.br/publique/cgi/cgilua.exe/sys/start.htm?UserActiveTemplate=fecomercio2008\&infoi $\mathrm{d}=12331 \&$ sid=90>. Acesso em: 04 mar. 2016.

FERRELL, O.; HARTLINE, M. Marketing strategy. Ohio: Cengage Learning, 2011.

FREITAS, D. Vídeo locadora estudo da atividade empresarial. 2004. Disponível em <http://201.2.114.147/bds/bds.nsf/63DDF5BAFDD4B00E83256E8300740B33/\$File/NT00048 B76.pdf>. Acesso em: 27 mar 2015.

Revista Eletrônica de Estratégia \& Negócios, Florianópolis, v.9, n.1, jan./abr. 2016. 
GALVÃO, N.; DE SOUSA MELO, R. O método de análise SWOT como ferramenta para promover o diagnóstico turístico de um local: o caso do município de Itabaiana (PB). Caderno Virtual de Turismo, v. 8, n. 1, p. 118-130, 2008.

GEORGOFF, D.; MURDICK, R. Manager's guide to forecasting. Harvard Business Review, v. 64, n. 1, p. 110 - 120, 1986.

GODET, M. How to be rigorous with scenarios planning. Foresight, v. 2, n. 1, p. 5 -9, 2000.

GRAVE, P.; SEIXAS, R. Diagnóstico organizacional: elementar, meu caro administrador! Anais do 9o Encontro Nacional dos Cursos de Graduação em Administração - ENANGRAD 1998, Itu/SP, 1998.

HAIR, J.; ANDERSON, R.; TATHAM, R.; BLACK, W. Multivariate date analysis. Englewood Cliffs, NJ: Prentice-Hall, 2009.

HAX, A.; MAJLUF, N. Strategic management: an integrative perspective. New Jersey: Englewood Cliffs, 1984.

HOOLEY, G.; PIERCY, N.; NICOULAUD, B. Marketing strategy and competitive positioning. London: Prentice Hall, 2012.

HUDSON, R. Marketing situation analysis and strategic planning for NHS clinical services. Journal of Management \& Marketing in Healthcare, v. 3, n. 3, p. 224-238, 2010.

JOHNSON, R.; ONWUEGBUZIE, A.; TURNER, L. Toward a definition of mixed methods research. Journal of Mixed Methods Research, v. 1, n. 2, p. 112-133, 2007.

KAMAKURA, W.; MITTAL, V.; DE ROSA, F.; MAZZON, J. Assessing the service-profit chain. Marketing Science, v. 21, n. 3, p. 294-317, 2002.

MALHOTRA, N. Marketing research: an applied orientation. Uttar Pradesh: Pearson Education India, 2008.

McDONALD, M. Strategic marketing planning: theory and pratice. The Marketing Review, n.4, p. 375-418, 2006.

MORGAN, G. Imagens da organização. São Paulo: Atlas, 1996.

OLHAR DIGITAL. Brasil é 4 em lista de pirataria de filmes na Internet, 2014. Disponível em: $<$ http://olhardigital.uol.com.br/noticia/brasil-e-4-em-lista-de-pirataria-de-filmes-nainternet/42706>. Acesso em: 04 de mar. 2016.

PEREIRA, M.; GRAPEGGIA, M.; EMMENDOERFER, M.; TRÊS, D. Fatores de inovação para a sobrevivência das micro e pequenas empresas no brasil. Revista de Administração e Inovação, v. 6, n. 1, p. 50-65, 2009.

PIZZINATTO, N.; SILVA, D. Relação entre o planejamento estratégico e o planejamento de marketing. In: ACEVEDO, C. R. (org.). Fundamentos de marketing. Itu/SP: Ottoni Editora, 2009, p. 218-233.

Revista Eletrônica de Estratégia \& Negócios, Florianópolis, v.9, n.1, jan./abr. 2016. 
PORTER, M. Competitive strategy: techniques for analyzing industries and competitors. New York: Simon and Schuster, 2008.

RADONS, D.; TORRES, C.; CERETTA, P. Mensuração da satisfação de clientes com serviços de fast food. Revista Eletrônica de Estratégia \& Negócios, v. 5, n. 3, p. 122-150, 2013.

RADULESCU, V.; CETINA, I. Customer analysis, defining component of marketing audit. Procedia Social and Behavioral Sciences, n. 62, p. 308-312, 2012.

RITTER, A.; DA SILVA, E.; DOS SANTOS, E.; BARBOSA, J.; SILVA, L.; CASTRO NETO, M.; MASCARENHAS, C. Utilização do planejamento estratégico em uma videolocadora. IX Encontro Latino Americano de Pós-Graduação - Universidade do Vale do Paraíba. São José dos Campos/SP, 2009.

SACRINI. M, O uso da televisão digital no contexto educativo. Revista Educação Temática Digital, v.7, n.1, p.31-44. 2005.

SARQUIS, A. Marketing para pequenas empresas: a indústria da confecção. São Paulo: Senac, 2003.

SARQUIS, A. Estratégias de marketing para serviços: como as organizações de serviços devem estabelecer e implementar estratégias de marketing. São Paulo: Atlas, 2009.

SARQUIS, A.; PIZZINATTO, N. Modelo de diagnóstico mercadológico no setor de serviços. Anais do XXXVI Encontro da ANPAD - ENANPAD 2012, Rio de Janeiro/RJ, 2012.

SARQUIS, A.; PIZZINATTO, N.; GALEANO, R.; PITOMBO, T.; PEREIRA, M. Modelo de diagnóstico mercadológico en el sector de serviços. Revista Invenio, v. 15, n. 29, p. 29-44, 2012.

SARQUIS, A.; PIZZINATTO, N. Modelo de processo de diagnóstico mercadológico para organizações de serviços de pequeno e médio portes. Revista de Negócios, v. 18, n. 2, p.81100, 2013.

SASSER, W.; SCHLESINGER, L.; HESKETT, J. Service profit chain. New York: Simon \& Schuster, 1997.

SCHNEIDER, A.; MACHADO, M. Planejamento estratégico: Deccory Com. e Serv. de Pintura Ltda. Revista Interdisciplinar Científica Aplicada, v. 1, n. 2, p. 1-20, 2008.

SILVA, L; LOPES, M.; OLIVEIRA, P. A mudança no mercado de videolocadoras sob a perspectiva da ecologia das populações organizacionais. Ciências Sociais em Perspectiva, v. 12, p. 1-19, 2013.

SILVEIRA, A.; ERDMANN, R. Ferramenta de Diagnóstico para Organizações Complexas, 2010. Anais do 34 Encontro da ENANPAD. Rio das Pedras/RJ, 2010.

TAM, J. Customer satisfaction, service quality and perceived value: an integrative model. Journal of Marketing Management, v. 20, n. 7-8, p. 897-917, 2004. 
VICENTINI, G.; DOMINGUES, M. O uso do vídeo como instrumento didático e educativo em sala de aula. Encontro Nacional dos Cursos de Graduação em Administração

(ENANGRAD). Anais, XIX ENANGRAD, Curitiba/PR, 2008.

WESTWOOD, J. How to write a marketing plan. London: Kogan Page Limited, 2006.

WYCKOFF, D. New tools for achieving service quality. Cornell Hotel and Restaurant Administration Quarterly, v. 25, n.3, p.78-91, 1984. 